This document is the accepted manuscript version of the following article:

Li, X., Snellings, R., Antoni, M., Alderete, N. M., Ben Haha, M., Bishnoi, S., Cizer, Ö., Cyr, M., De Weerdt, K., Dhandapani, Y., Duchesne, J., Haufe, J., Hooton, D., Juenger, M., Kamali-Bernard, S., Kramar, S., Marroccoli, M., Joseph, A. M., Parashar, A., ... Scrivener, K. L. (2018). Reactivity tests for supplementary cementitious materials: RILEM TC 267-TRM phase 1. Materials and Structures, 51(6), 151 (14 pp.).

https://doi .org/10.1617/s11527-018-1269-x

\title{
Reactivity tests for supplementary cementitious materials: RILEM TC 267- TRM phase 1
}

Xuerun $\mathrm{Li}^{1}$, Ruben Snellings, Mathieu Antoni, Natalia Mariel Alderete, Mohsen Ben Haha, Shashank Bishnoi, Özlem Cizer, Martin Cyr, Klaartje De Weerdt, Yuvaraj Dhandapani, Josée Duchesne, Johannes Haufe, Doug Hooton, Maria Juenger, Siham Kamali-Bernard, Sabina Kramar, Milena Marroccoli, Aneeta Mary Joseph, Anuj Parashar, Cedric Patapy, John L. Provis, Sergio Sabio, Manu Santhanam, Laurent Steger, Tongbo Sui, Antonio Telesca, Anya Vollpracht, Felipe Vargas, Brant Walkley, Frank Winnefeld, Guang Ye, Maciej Zajac, Shizhe Zhang, Karen L. Scrivener

\footnotetext{
${ }^{1}$ X. Li, K.L. Scrivener, Laboratory of Construction Materials, Swiss Federal Institute of Technology in Lausanne (EPFL), Station 12, CH-1015 Lausanne, Switzerland, e-mail: karen.scrivener@epfl.ch, xuerun.li@epfl.ch,

R. Snellings, Sustainable Materials Management, Flemish Institute of Technological Research (VITO), Boeretang 200, 2400 Mol, Belgium, email: ruben.snellings@vito.be

M. Antoni, Holcim Technology Ltd. Im Schachen, 5113 Holderbank, Switzerland

A. Mary Joseph, Natalia Mariel Alderete, Magnel Laboratory for Concrete Research, Technologiepark Zwijnaarde 904, 9052 Ghent, Belgium

M. Ben Haha, M. Zajac, HeidelbergCement Technology Center GmbH, Rohrbacher Str. 95, 69181 Leimen, Germany

A. Parashar, S. Bishnoi, Department of Civil Engineering, Indian Institute of Technology Delhi, Hauz Khas, New Delhi 110016 , India

Ö. Cizer, KU Leuven, Department of Civil Engineering, Kasteelpark Arenberg 40 - box 2448, 3001 Leuven, Belgium

L. Steger, C. Patapy, M. Cyr, Institut National des Sciences Appliquées (INSA Toulouse), LMDC-Département Génie Civil, Avenue de Rangueil 135, 31077 Toulouse Cedex 4, France

K. De Weerdt, Department of Structural Engineering, Norwegian University of Science and Technology, Trondheim, Norway

M. Santhanam, Y. Dhandapani, Department of Civil Engineering, IIT Madras, 600036 Chennai, India

J. Duchesne, Department of Geology and Geological Engineering, Université Laval, QC, Canada G1V 0A6

J. Haufe, A. Vollpracht, Institute of Building Materials Research, RWTH Aachen University, Schinkelstr. 3, 52062 Aachen, Germany

D. Hooton, O. Perebatova, Dept. of Civil Engineering, 35 St. George St., Toronto, ON, Canada M5S1A4

M. Juenger, Department of Civil, Architectural and Environmental Engineering, University of Texas at Austin, $301 \mathrm{E}$. Dean Keeton St., Austin, TX 78712, USA

S. Kamali-Bernard, Institut National des Sciences Appliquées (INSA Rennes), Laboratoire de Génie Civil et Génie Mécanique/LGCGM, 20, Avenue des Buttes de Coësmes, CS 70839, F - 35708 Rennes Cedex 7, France

S. Kramar, ZAG-Slovenian National Building and Civil Engineering Institute, Dimičeva ulica 12, 1000 Ljubljana, Slovenia M. Marroccoli, A. Telesca, Scuola di Ingegneria, Università degli Studi della Basilicata, Viale dell'Ateneo Lucano, 10, 85100 Potenza, Italy

J.L. Provis, B. Walkley, Department of Materials Science and Engineering, The University of Sheffield, Sheffield S1 3JD, United Kingdom

S. Sabio, Lafarge Research Center, 95 Rue du Montmurier, 38290 France

T. Sui, B. Wang, Sinoma Research Institute, Sinoma International Engineering Co., Ltd, No. 16 Wangjing North Road, Chaoyang District, Beijing 100102, P.R. China

F. Vargas, Department of Construction Engineering and Management, School of Engineering, Pontificia Universidad Catolica de Chile, Vicuna Mackenna 4860, Casilla 306, Correo 22, Santiago, Chile

F. Winnefeld, Laboratory for Concrete and Construction Chemistry, Empa, Swiss Federal Laboratories for Materials Science and Technology, Überlandstrasse 129, 8600 Dübendorf, Switzerland

G. Ye, S. Zhang, Microlab/Section Materials \& Environment, Faculty of Civil Engineering and Geosciences, Delft University of Technology, Building 23, Stevinweg 1, 2628 CN Delft, The Netherlands
} 


\begin{abstract}
:
A primary aim of RILEM TC 267-TRM: "Tests for Reactivity of Supplementary Cementitious Materials (SCMs)" is to compare and evaluate the performance of conventional and novel SCM reactivity test methods across a wide range of SCMs. To this purpose, a round robin campaign was organized to investigate 10 different tests for reactivity and 11 SCMs covering the main classes of materials in use, such as granulated blast furnace slag, fly ash, natural pozzolan and calcined clays. The methods were evaluated based on the correlation to the 28 days relative compressive strength of standard mortar bars containing $30 \%$ of SCM as cement replacement and the interlaboratory reproducibility of the test results.

It was found that only a few test methods showed acceptable correlation to the 28 days relative strength over the whole range of SCMs. The methods that showed the best reproducibility and gave good correlations used the $\mathrm{R}^{3}$ model system of the $\mathrm{SCM}$ and $\mathrm{Ca}(\mathrm{OH})_{2}$, supplemented with alkali sulfate/carbonate. The use of this simplified model system isolates the reaction of the SCM and the reactivity can be easily quantified from the heat release or bound water content. Later age (90 d) strength results also correlated well with the results of the IS 1727 (Indian standard) reactivity test, an accelerated strength test using an $\mathrm{SCM} / \mathrm{Ca}(\mathrm{OH})_{2}$-based model system. The current standardized tests did not show acceptable correlations across all SCMs, although they performed better when latently hydraulic materials (blast furnace slag) were excluded. However, the Frattini test, Chapelle and modified Chapelle test showed poor interlaboratory reproducibility, demonstrating experimental difficulties. The TC 267-TRM will pursue the development of test protocols based on the $\mathrm{R}^{3}$ model systems. Acceleration and improvement of the reproducibility of the IS 1727 test will be attempted as well.
\end{abstract}

Keywords: supplementary cementitious materials, reactivity test, heat release, bound water, compressive strength

This report was prepared by members within RILEM TC 267-TRM "Tests for Reactivity of Supplementary Cementitious Materials". The report has been reviewed and approved by all members of the RILEM TC 267TRM.

TC membership:

TC Chair: Karen L. Scrivener.

TC Deputy Chair: Ruben Snellings.

TC Members: Natalia ALDERETE, Mathieu ANTONI, Mohsen BEN HAHA, Susan BERNAL LOPEZ, Shashank BISHNOI, Özlem CIZER, Martin CYR, Nele DE BELIE, Klaartje DE WEERDT, Yuvaraj DHANDAPANI, Josée DUCHESNE, Pawel DURDZINSKI, Johannes HAUFE, R. Doug HOOTON, Edgardo IRASSAR, Aneeta Mary JOSEPH, Maria C. Garci JUENGER, Siham KAMALI-BERNARD, Sabina KRAMAR, Xuerun LI, Milena MARROCCOLI, Thomas MATSCHEI, Toyoharu NAWA, Marta PALACIOS, Anuj PARASHAR, Cédric PATAPY, Malene PEDERSEN, John L. PROVIS, Serge SABIO, Manu 
SANTHANAM, Karen SCRIVENER, Ruben SNELLINGS, Laurent STEGER, Tongbo SUI, Antonio TELESCA, Dr. Karl - Christian THIENEL, Felipe VARGAS, YurY VILLAGRAN ZACCARDI, Anya VOLLPRACHT, Brant WALKLEY, Frank WINNEFELD, Guang YE, Maciej ZAJAC, Shizhe ZHANG

\section{Introduction}

The use of supplementary cementitious materials (SCMs) as a partial replacement for clinker in blended cements or concrete is becoming increasingly widespread. In addition, the availability of traditionally used SCMs (e.g. blast furnace slag and fly ash) is decreasing and a wider range of materials and combination are being considered as SCMs. The first criterion for such replacements is the contribution they make to the development of mechanical properties, so there is great interest both in testing this directly and in the development of tests which give a rapid assessment of this reactivity. RILEM TC 267-TRM (Tests for Reactivity of Supplementary Cementitious Materials) was established to evaluate the existing reactivity tests and develop a pre-normative recommendation for rapid SCM reactivity tests that can be adopted as standard testing methods. Ideally test methods should supply results more rapidly than the standard compressive strength testing regimes, they should be straightforward and robust to execute, and should not require expensive equipment or advanced training of practitioners.

The current standardized methods for SCM or pozzolanic reactivity test are: 1) the Chapelle test [1] or a modified version of it (NF P18-513) [2], 2) the Frattini pozzolanicity test (EN 196-5) [3], and 3) the determination of reactive silica (EN 197-1/EN 196-2:2013). An Indian standard (IS 1727-1967) - locally known as the lime reactivity test - is also in use. Both the (modified) Chapelle [1,2,4] and Frattini test methods [3,4] measure the reactivity of the $\mathrm{SCM}$ with $\mathrm{Ca}(\mathrm{OH})_{2}$, either by titrating the amount of $\mathrm{Ca}(\mathrm{OH})_{2}$ remaining in a dilute suspension or by evaluating the saturation degree of solution towards $\mathrm{Ca}(\mathrm{OH})_{2}$, respectively. Both tests intend to test pozzolanic reactivity (with portlandite) and were not intended to work for latent-hydraulic, Ca-rich SCM such as blast furnace slags or high calcium fly ashes. The Chapelle test takes less than 1 day to carry out, the Frattini test at least 8 days, and for less reactive SCMs up to 15 days. The IS 1727 test measures the compressive strength of a portlandite $\left(\mathrm{Ca}(\mathrm{OH})_{2}\right)$ and SCM binary mix cured initially at $27{ }^{\circ} \mathrm{C}$ and then at $50{ }^{\circ} \mathrm{C}$ until 10 days after casting. Previous work, indicated that some of these standard reactivity testing methods for SCMs have shortcomings [4], particularly in terms of correlation to strength development of cements, test duration and reproducibility.

There has been much research on the mechanism of reaction of SCMs in blended systems, which has benefited from advances in analytical methods and thermodynamic modelling [5,6]. In contrast, few advances have been made regarding reactivity test methods.

More recently, the spread of new or improved experimental techniques such as isothermal conduction calorimetry has inspired new research into the topic $[7,8]$. The so called " $\mathrm{R}^{3 \text { " }}$ test was developed initially to test 
the pozzolanic activity of calcined clays [7]. $\mathrm{R}^{3}$ stands for rapid, reproducible and relevant: the aim is to have a method which can give results correlating to strength in standard mortars (relevant) in a much shorter time (rapid) and which is relatively simple to carry out giving reproducible results. This method is intended to better simulate the conditions occurring in a blended cement by the addition of small amounts of sulfate and alkali to an SCM portlandite mixture. This test was accelerated by measuring the reaction at $40{ }^{\circ} \mathrm{C}$ either by the heat release in isothermal calorimetry continuously up to 7 days, or bound water between 110 and $400{ }^{\circ} \mathrm{C}$ after 7 days of curing. For calcined clay a very good correlation was found between the amount of reaction at 1 day at $40{ }^{\circ} \mathrm{C}$ and the 28-day strength in standard mortar bars.

This paper reports on the round robin study which was phase 1 of the committee work. The objective was to look at the performance of a range of methods proposed to measure reactivity across a wide range of SCMs. The test methods were selected according to the experience of the committee members and an overview of SCM reactivity tests [4]. Two categories of test methods were defined: the existing standard methods, and the $\mathrm{R}^{3}$ model system tests (non-standard). For the $\mathrm{R}^{3}$ system, measurements of portlandite consumption using thermogravimetric analysis (TG) [9], and chemical shrinkage [10] were included in addition to the calorimetry and bound water methods.

The reactivity test results for a selection of SCMs were compared to a benchmark - the compressive strength results of cement mortar bars (EN 196-1) - in which 30 wt. \% of the Portland cement was replaced by the SCM. The interlaboratory reproducibility of the test methods was assessed. A selection of test methods which seem to be giving best results for further testing and optimization was made for the phase 2 work of this committee.

\section{Experimental}

\subsection{Participants and work plan}

In total, there were 21 participants (see Table 1), who were free to choose which methods to test. The summary of the number of participants for each test is shown in Table 2.

Table 1 Summary of the participants

\begin{tabular}{|c|c|c|c|c|}
\hline Continent & \multicolumn{2}{|r|}{ Europe } & North America & Asia \\
\hline \multirow{4}{*}{ 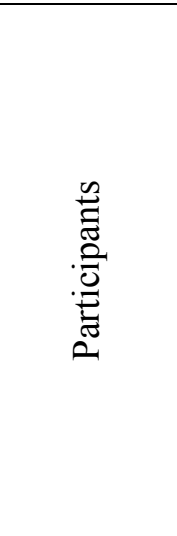 } & Empa (CH) & RWTH Aachen University (DE) & $\begin{array}{l}\text { Université Laval } \\
\text { (CA) }\end{array}$ & $\begin{array}{c}\text { Indian Institute } \\
\text { of Technology } \\
\text { Delhi (IN) }\end{array}$ \\
\hline & EPFL (CH) & Delft University of Technology (NL) & $\begin{array}{l}\text { University of } \\
\text { Texas at Austin } \\
\text { (US) }\end{array}$ & $\begin{array}{l}\text { Indian Institute } \\
\text { of Technology } \\
\text { Madras (IN) }\end{array}$ \\
\hline & LafargeHolcim (FR) & $\begin{array}{l}\text { Università degli Studi della Basilicata } \\
\text { (IT) }\end{array}$ & $\begin{array}{l}\text { University of } \\
\text { Toronto (CA) }\end{array}$ & $\begin{array}{c}\text { Sinoma } \\
\text { Research } \\
\text { Institute }(\mathrm{CN})\end{array}$ \\
\hline & $\begin{array}{l}\text { HeidelbergCement } \\
\text { Technology Center } \\
\text { (DE) }\end{array}$ & Ghent University (BE) & & \\
\hline
\end{tabular}




\begin{tabular}{|c|c|c|c|c|}
\hline & $\begin{array}{c}\text { Institut national des } \\
\text { sciences appliquées de } \\
\text { Rennes (FR) }\end{array}$ & The University of Sheffield (GB) & & \\
\hline & $\begin{array}{c}\text { Institut national des } \\
\text { sciences appliquées de } \\
\text { Toulouse (FR) }\end{array}$ & $\begin{array}{l}\text { Flemish Institute of Technological } \\
\text { Research, VITO (BE) }\end{array}$ & & \\
\hline & KU Leuven (BE) & $\begin{array}{l}\text { ZAG-Slovenian National Building and } \\
\text { Civil Engineering Institute (SI) }\end{array}$ & & \\
\hline & $\begin{array}{c}\text { Norwegian University } \\
\text { of Science and } \\
\text { Technology (NO) }\end{array}$ & & & \\
\hline Subtotal & & 15 & 3 & 3 \\
\hline Total & & 21 & & \\
\hline
\end{tabular}

Notes: country codes were indicated in the brackets.

Table 2 Summary of the test planning.

\begin{tabular}{|c|c|c|}
\hline & Test & Total participants \\
\hline \multirow{6}{*}{ 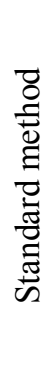 } & Mortar test: EN 196-1 & 6 \\
\hline & Frattini test: EN 196-5 & 5 \\
\hline & Chapelle test: standard & 4 \\
\hline & $\begin{array}{l}\text { Modified Chapelle test: } \\
\text { NF P18-513 }\end{array}$ & 5 \\
\hline & IS 1727 (Indian standard) & 2 \\
\hline & $\begin{array}{l}\text { Reactive silica: EN 197- } \\
\text { 1/EN 196-2 }\end{array}$ & 1 \\
\hline \multirow{4}{*}{$\begin{array}{c}\bar{q} \\
\bar{O} \\
\Xi \\
\tilde{\approx} \\
\tilde{\approx}\end{array}$} & Calorimetry & 13 \\
\hline & Bound water & 13 \\
\hline & Chemical shrinkage & 5 \\
\hline & Portlandite consumption & 7 \\
\hline
\end{tabular}

\section{2 $\mathrm{SCMs}$}

In this phase 1, the aim was to look at a wide range of SCMs, including those most commonly used. Eleven materials, were selected:

- 2 calcined clays (labelled as $C C 1$ and $C C 2$ )

- 2 ground granulated blast-furnace slags (labelled as $S 1$ and $S 8$ )

- $\quad 2$ calcareous fly ashes from coal combustion (labelled as $C F A \_P$ and $C F A \_S$ )

- 3 siliceous fly ashes from coal combustion (labelled as $S F A_{-} E, S F A_{-} I$ and $S F A_{-} R$ )

- 1 natural pozzolan (labelled as $P o$ )

- quartz (labelled as $Q$ ) as a reference for an inert material

The Supplementary Material (can be downloaded via the link at the end of the paper) gives the chemical composition (measured by X-ray fluorescence analysis); origin and the physical properties of the SCMs (Blaine fineness, density measured according to ASTM C188-09 using isopropanol instead of kerosene [11]; particle 
size distribution (PSD) measured using Malvern laser diffraction using isopropanol); and mineralogical compositions of the materials obtained by X-ray powder diffraction (XRD) with Rietveld analysis. For SCMs, the external standard method was used to determine the amorphous content (details on the XRD experiments and Rietveld analysis are given in the Supplementary Material).

\subsection{Benchmark testing}

It was decided to use a conventional strength test as a benchmark for the reactivity tests. The level of replacement of the SCMs was chosen as $30 \mathrm{wt}$. \% to give good sensitivity to the contribution of the SCMs.

Six participants carried out the mortar strength tests according to EN 196-1 using local Portland cements (in total 6 different cements were used) of type CEM I $42.5 \mathrm{~N} / \mathrm{R}$ or similar. The characteristics of the cements used for the mortar tests are given in the Supplementary Material.

An adjustment of gypsum content (similar to Antoni et. al. [12]) was applied and a superplasticizer (PCE type) was introduced for calcined clays to control the reaction of the $\mathrm{Al}_{2} \mathrm{O}_{3}$ in the SCMs and the workability of the mortar, respectively. The compressive strength was measured at 2, 7, 28 and 90 days.

It was not possible to average the absolute strengths for the different cements as 6 local CEM I $42.5 \mathrm{~N} / \mathrm{R}$ cements were used. So, the relative compressive strength $R_{S C M}$, relative $(\%)$ was used for the correlation analysis:

$R_{S C M, \text { relative }}=\frac{R_{S C M}-R_{P C}}{R_{P C}} \times 100 \quad$ Eq. (1),

where $R_{S C M}$ and $R_{P C}$ are the absolute strength in MPa for the SCM blended cement and the pure PC from the same source, respectively. $R_{S C M}$,relative was calculated for each cement and then averaged. The strengths relative to the quartz-containing references were also calculated.

\subsection{Methods}

Detailed protocols for each of the methods are given in the Supplementary Material.

\subsection{Standard SCM reactivity tests}

The standardized methods used were:

1) Chapelle test or a modified version of it (NF P18-513)

The Chapelle test [1] assesses the consumption of calcium hydroxide by a test material in a dilute heated suspension as a measure of pozzolanic activity. $1 \mathrm{~g}$ of SCM reacts with 1 or $2 \mathrm{~g}$ of $\mathrm{Ca}(\mathrm{OH})_{2}$ (Chapelle or modified Chapelle test, respectively) in $200 \mathrm{~mL}$ of water at $90-100{ }^{\circ} \mathrm{C}$ for $16 \mathrm{~h}$. The non-reacted lime is then analyzed and the result is expressed in $\mathrm{mg} \mathrm{Ca}(\mathrm{OH})_{2}$ fixed by the SCM.

2) Frattini or pozzolanicity test (EN 196-5) 
The Frattini test evaluates portlandite saturation in a supernatant solution of a hydrated slurry of Portland cement and a pozzolanic test material by measuring the $\mathrm{OH}^{-}$and $\mathrm{Ca}^{2+}$ concentrations. The test consists of mixing a blend of Portland cement (CEM I) and SCM with distilled water at a water to solid ratio of 5. The interpretation of the Frattini test results was made according to Donatello et. al. [13] and Snellings et. al. [4], which calculates the vertical distance of data points from the lime solubility curve.

3) The determination of reactive silica (EN 196-2 and EN 197-1)

Reactive silica is defined according to EN 197-1 as that fraction of the $\mathrm{SiO}_{2}$ which is soluble after treatment with $\mathrm{HCl}$ and a boiling $\mathrm{KOH}$ solution. The measurement procedure is established in EN 196-2.

4) The Indian test method for pozzolanic materials (IS 1727 - 1967)

In this method, a volume based mix design is used to keep the same volume of the binder in each mix. A 1:2:6 portlandite: pozzolan : sand ratio is used and the water/binder $(\mathrm{w} / \mathrm{b})$ ratio is adapted to keep the mortar flow fixed. The mortars are cast and kept in RH saturated conditions and at $27^{\circ} \mathrm{C}$ until 2 days, after which the samples are demolded and further cured at $90-100 \% \mathrm{RH}$ and $50{ }^{\circ} \mathrm{C}$. The compressive strength of the mortar cubes is measured after 10 days of curing. The strength data are taken as indication of the reactivity of the pozzolan.

\section{$2.6 \quad \mathrm{R}^{3}$ methods}

The basic principle of the $\mathrm{R}^{3}$ test methods is to use a simplified model system to separately measure the reaction of an SCM. This is to avoid interference and overlap with the clinker hydration reactions that occur in a blended cement system. Moreover, the use of lab-grade chemicals instead of local Portland cements avoids much material related variability. The two main components of the $\mathrm{R}^{3}$ test methods are the $\mathrm{SCM}$ and $\mathrm{Ca}(\mathrm{OH})_{2}$. The mix design of the $\mathrm{R}^{3}$ model paste, shown in Table 3, was based on the work of Avet et al. [7].

Table $3 R^{3}$ model mix design

\begin{tabular}{ccccccc}
\hline Components & SCM & Portlandite $^{(\mathrm{a})}$ & Deionized Water & $\mathrm{KOH}^{(\mathrm{b})}$ & $\mathrm{K}_{2} \mathrm{SO}_{4}{ }^{(\mathrm{b})}$ & Calcite $^{(\mathrm{c})}$ \\
\hline Mass (g) & 11.11 & 33.33 & 60.00 & 0.24 & 1.20 & 5.56 \\
\hline
\end{tabular}

Notes: (a) Lab-grade, less than 5 wt. $\% \mathrm{CaCO}_{3}$ present

(b) Lab-grade

(c) Lab-grade, $\mathrm{d}_{50} 5-15 \mu \mathrm{m}$.

The $\mathrm{R}^{3}$ pastes were used for the bound water, isothermal calorimetry, portlandite consumption using TG and the chemical shrinkage tests.

$R^{3}$ bound water 
The $\mathrm{R}^{3}$ pastes were cured in sealed plastic containers at $40{ }^{\circ} \mathrm{C}$ for 7 days. The hydrated samples were crushed and dried in an oven at $105^{\circ} \mathrm{C}$ until reaching constant weight. The dried samples were heated at $350{ }^{\circ} \mathrm{C}$ for 2 hours and the bound water (for hydrates, excluding portlandite) was calculated from the weight difference.

\section{$R^{3}$ portlandite consumption}

The $\mathrm{R}^{3}$ pastes were cured in a sealed container at $40{ }^{\circ} \mathrm{C}$ for 7 days. The hydration of the samples was stopped by solvent exchange according to $[14,15]$. The dried samples were analyzed by thermogravimetry. $50 \mathrm{mg}$ of sample was introduced in the crucible which was heated from $30{ }^{\circ} \mathrm{C}$ to $950{ }^{\circ} \mathrm{C}$ at $10{ }^{\circ} \mathrm{C} / \mathrm{min}$. A protective nitrogen atmosphere at a flow rate of $50 \mathrm{~mL} / \mathrm{min}$ was used. The portlandite content was determined using the tangent method described by Lothenbach et al. [16] and the portlandite consumption calculated by difference to the initial content.

\section{$R^{3}$ calorimetry test}

Isothermal conduction calorimetry at $40{ }^{\circ} \mathrm{C}$ was carried out to measure the heat release during hydration of the $\mathrm{R}^{3}$ systems. The heat release was recorded until 7 days.

$R^{3}$ chemical shrinkage

Chemical shrinkage was measured using a modified protocol based on ASTM C1608-12 and Geiker [17]. 4-6 replicate samples were used for all measurements. The fresh $\mathrm{R}^{3}$ paste was added into the test vial (weight $m_{\text {vial }}$ ) up to $\sim 3 \mathrm{~cm}$ (half to two thirds of the container's capacity). De-aerated water at $40^{\circ} \mathrm{C}$ was carefully added on top, avoiding mixing with the paste to completely fill the vial. The sealed samples were placed in a water bath at $40{ }^{\circ} \mathrm{C}$ and the volume changes were recorded for 14 days to calculate the chemical shrinkage.

\subsection{Data treatment}

The inputs from different participants for the same test were averaged, and the standard deviation $(\sigma)$ on the average of the test results was calculated.

The coefficient of variation ( $\mathrm{CV}$, in \%) was used to estimate the reproducibility of a test between laboratories: the smaller the $\mathrm{CV}$, the higher the reproducibility. For the calculation of the $\mathrm{CV}$, the difference between the averages of the SCM and the quartz results were used in the denominator. This way the quartz acts as the reference and comparison of the $\mathrm{CV}$ amongst samples and techniques is possible.

$$
C V_{i}=\frac{\sigma_{i}}{\bar{x}_{\imath}-\bar{x}_{Q}} \times 100
$$

where $\sigma_{i}$ and $\bar{x}_{l}$ are the standard deviation and the mean of the input of a test method from all the laboratories for a specific SCM, respectively, and $\bar{x}_{Q}$ is the mean of the input from all laboratories for quartz for the test method. The mean CV of all the SCMs for a specific testing method was used to assess reproducibility of the method. 
Linear fitting of the data from the test methods to relative strength was used for all the SCMs tested. The regression coefficient, $R^{2}$, of the linear fitting was taken as the indicator of quality of correlation between the relative strength and the respective test method.

\section{Results}

The original data are reported in the Supplementary Material. The following sections present an overview of the processed results.

\subsection{Compressive strength benchmark test}

The strength development of the cement reference samples showed significant differences both at early ( 2 and 7 days) and late ages (28 and 90 days), even though the cements used for the mortar test were all CEM I 42.5N/R (see Supplementary Material). These differences were enlarged when the cements were blended with the SCMs. Even when the results were expressed relative to the reference cement, there were still large differences for the results from different laboratories.

The average of the relative strengths at 28 days was retained as the critical measure for comparison. For early and later strength, the average of the relative strengths at 7 days and 90 days were regarded as the indicators, respectively. The relative strength based rankings of the 10 SCMs and the quartz are shown in Figure 1 . The strengths relative to the quartz reference were also calculated, see Figure 1 (d). These show the same ranking (Figure 1 (b) and (d)). 

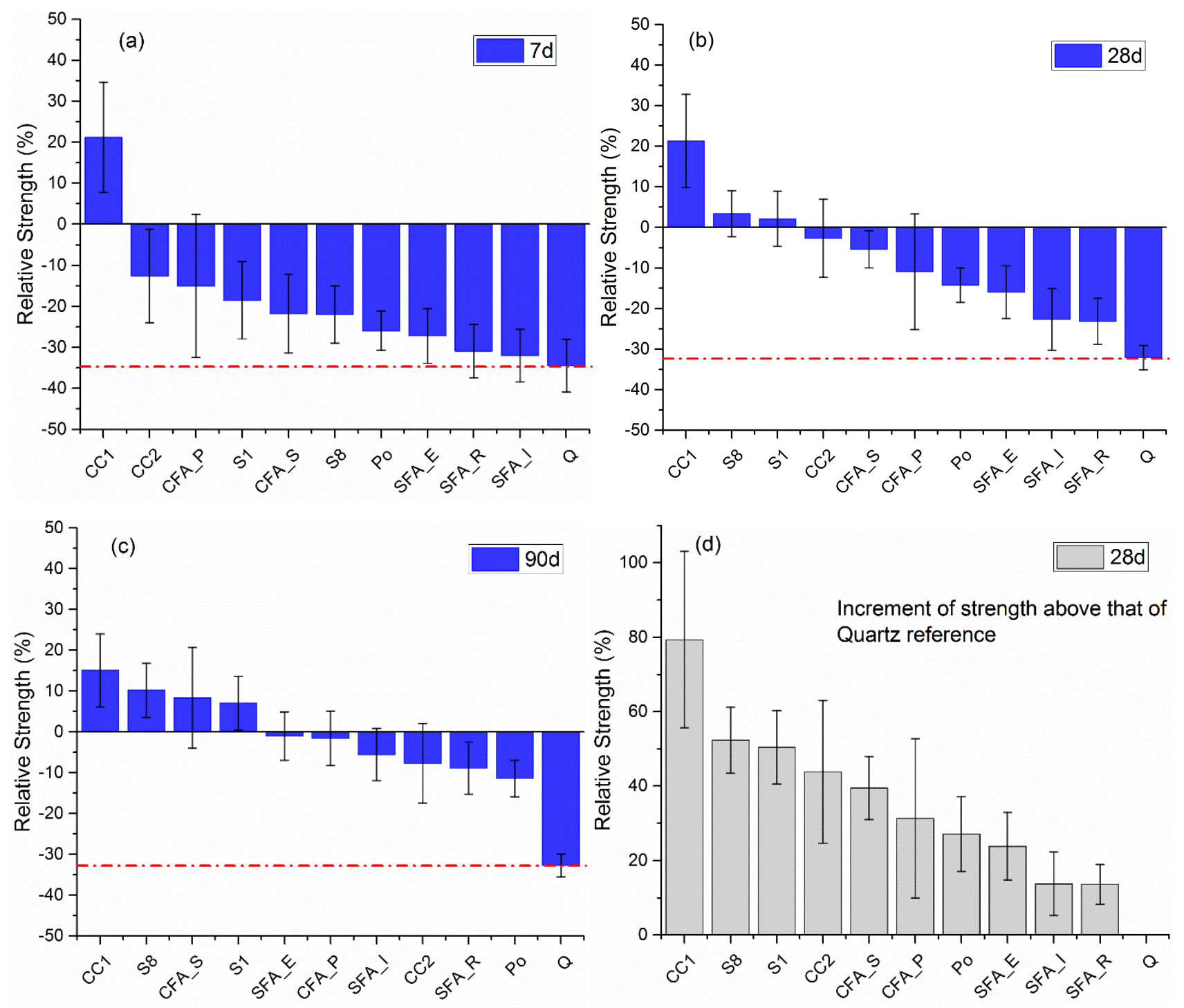

Figure 1 Relative strengths of the SCM blended cement mortar bars, (a), (b) and (c) are relative strengths compared to the PC reference, $(d)$ shows relative strength compared to the quartz $(Q)$ as inert reference

\subsection{Correlation analysis of reactivity test results}

The global average and the standard deviation of the output for each reactivity test are shown in Figure 2 and

Figure 3. Characteristic heat release and chemical shrinkage values at $0.5,1,3$ and 7 days (and 14 days for chemical shrinkage only) were used for the correlation analysis for continuous measurements such as $\mathrm{R}^{3}$ calorimetry and chemical shrinkage. The 3 and 7 days values are shown in the Supplementary Material. 

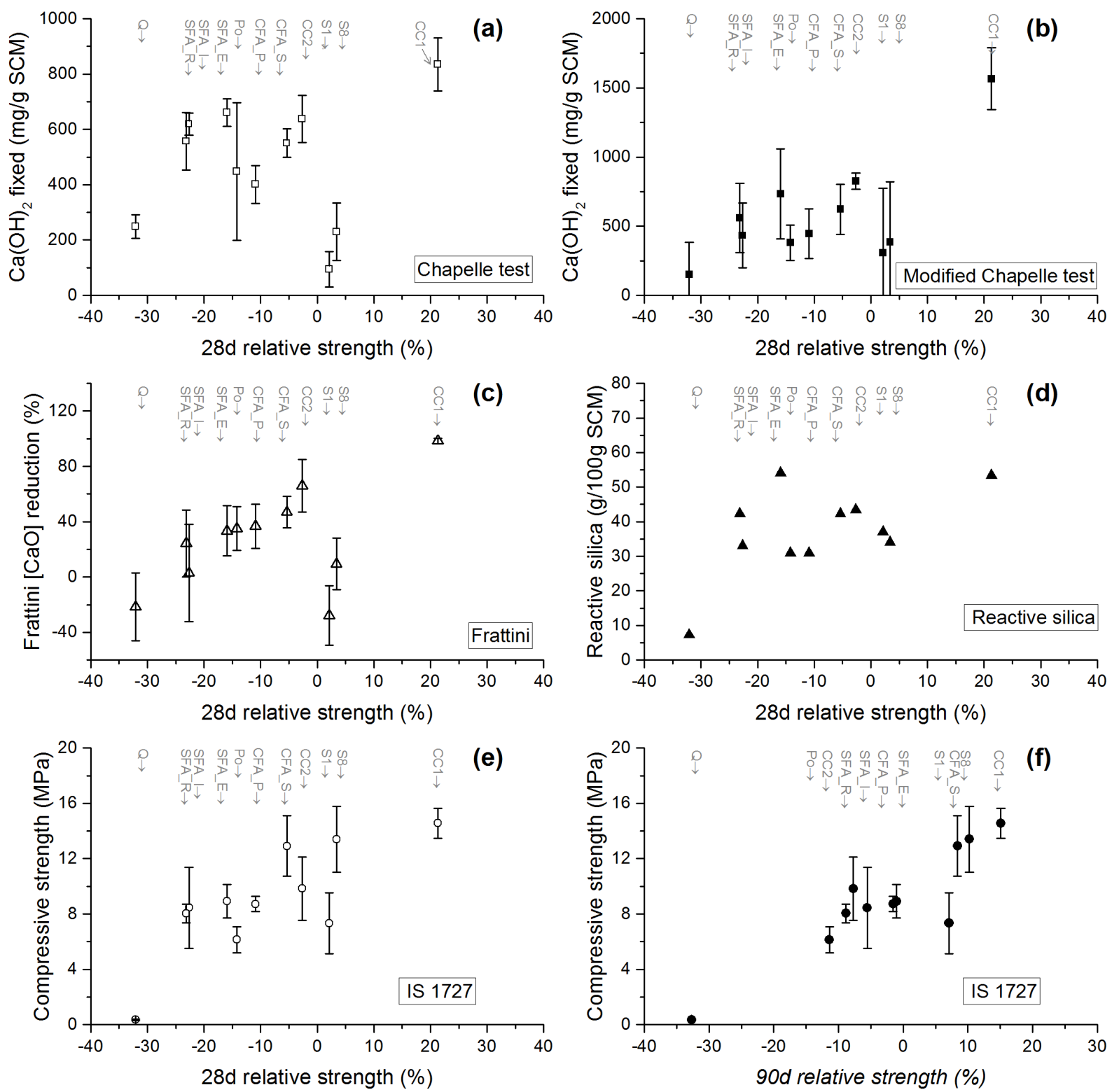

Figure 2 Plots of the results of standard testing methods compared against relative strength; the SCMs corresponding to the points are labelled on top of the plot. (a) Chapelle test, (b) modified Chapelle test, (c) Frattini test, (d) Reactive silica, no error bar because there is only 1 input, (e) IS 1727 and (f) IS 1727 (vs. 90 days relative strength). Average values are shown by symbols, the error bars represent $1 \sigma$. 

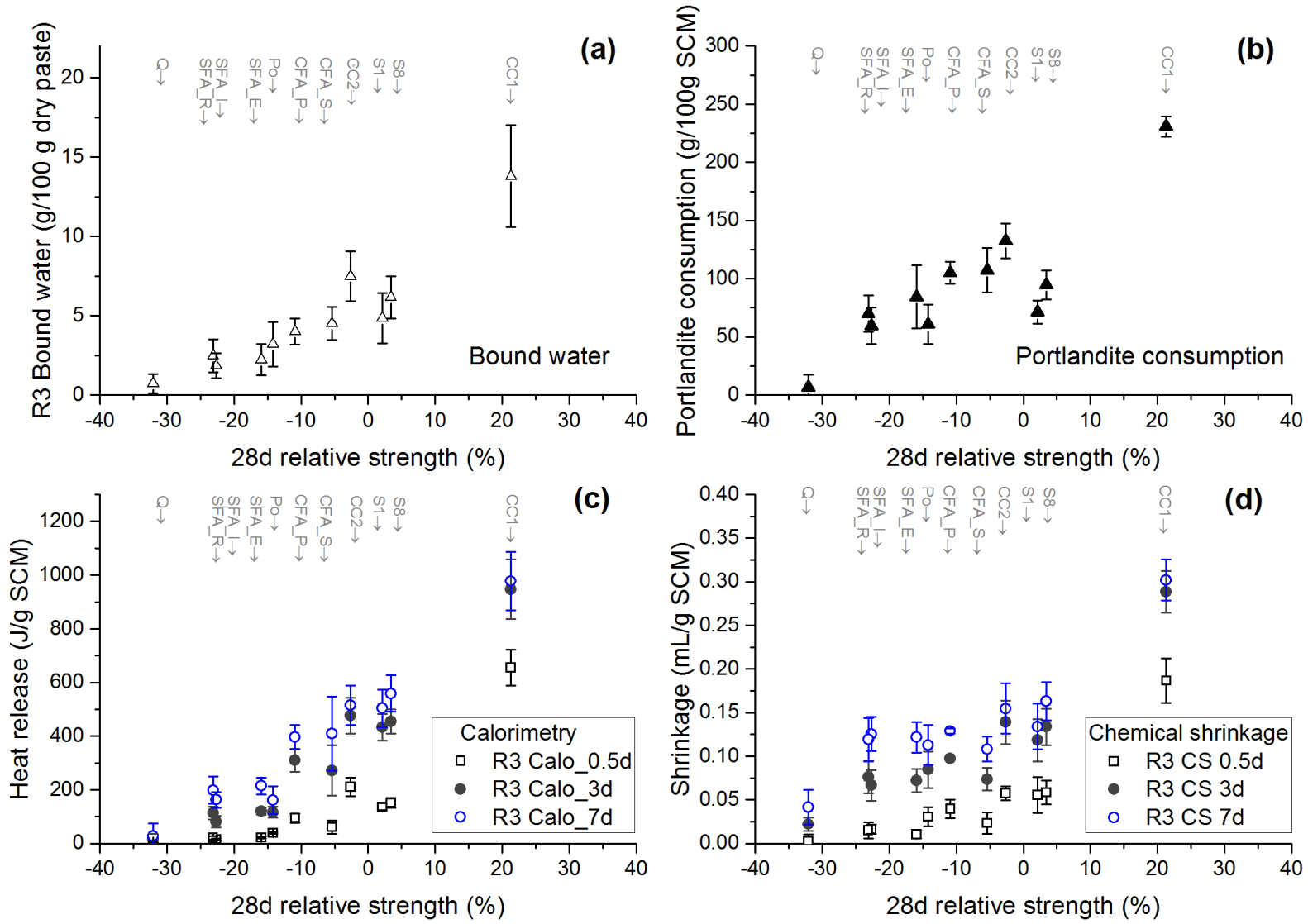

Figure 3 Plots of the $R^{3}$ model test methods to 28 days relative strength, the SCMs corresponding to the points are labelled on top of each plot. (a) Bound water test, (b) Portlandite consumption, (c) Cumulative heat release for 0.5, 3 and 7 days and (d) Chemical shrinkage at 0.5, 3 and 7 days. Average values are shown by symbols, the error bars represent $1 \sigma$.

The $R^{2}$ values of the linear correlation between the reactivity test results and the relative strength using all the SCMs (including the quartz) are summarized in Table $4^{2}$. Here we considered an $R^{2}$ of more than 0.85 as the criterion for acceptance in terms of correlation.

Table $4 R^{2}$ index of linear correlation of the reactivity test results to the relative strength at 7, 28 and 90 days for all SCMs tested.

\begin{tabular}{|c|c|c|c|c|c|c|c|c|c|c|c|c|c|c|c|c|}
\hline \multirow{3}{*}{$\begin{array}{c}\text { Relative } \\
\text { strength } \\
\quad \text { at }\end{array}$} & \multicolumn{5}{|c|}{ Standard method } & \multicolumn{11}{|c|}{ R3 model } \\
\hline & \multirow[b]{2}{*}{ Chapelle } & \multirow{2}{*}{$\begin{array}{l}\text { Modified } \\
\text { Chapelle }\end{array}$} & \multirow{2}{*}{$\begin{array}{c}\text { IS } \\
1727\end{array}$} & \multirow{2}{*}{$\begin{array}{c}\text { Frattini } \\
\mathrm{CaO}] \\
\text { reduction }\end{array}$} & \multirow{2}{*}{$\begin{array}{l}\text { Reactive } \\
\text { silica }\end{array}$} & \multirow{2}{*}{$\begin{array}{l}\text { Bound } \\
\text { water }\end{array}$} & \multirow{2}{*}{$\begin{array}{c}\mathrm{CH} \\
\text { consumed }\end{array}$} & \multicolumn{4}{|c|}{ Calorimetry (heat released) } & \multicolumn{5}{|c|}{ Chemical shrinkage } \\
\hline & & & & & & & & $0.5 d$ & $1 d$ & $3 d$ & $7 d$ & $0.5 d$ & $1 d$ & $3 d$ & $7 d$ & $14 d$ \\
\hline 7 days & 0.20 & 0.74 & 0.39 & 0.54 & 0.27 & 0.93 & 0.89 & 0.95 & 0.95 & 0.90 & 0.86 & 0.93 & 0.94 & 0.92 & 0.87 & 0.72 \\
\hline 28 days & 0.03 & 0.46 & 0.62 & 0.31 & 0.33 & 0.86 & 0.74 & 0.72 & 0.80 & 0.91 & 0.94 & 0.77 & 0.76 & 0.80 & 0.75 & 0.55 \\
\hline 90 days & 0.04 & 0.29 & 0.82 & 0.17 & 0.52 & 0.43 & 0.51 & 0.31 & 0.36 & 0.50 & 0.63 & 0.36 & 0.33 & 0.41 & 0.49 & 0.47 \\
\hline
\end{tabular}

${ }^{2}$ The $R^{2}$ values of the linear correlation of the relative strength to the quartz reference strength are given in the Supplementary Material 


\subsection{Interlaboratory reproducibility}

The coefficient of variation ( $\mathrm{CV}$ defined in Eq. (8)) was used to indicate the reproducibility of the reactivity test methods (see Figure 4). As there was only one participant for the reactive silica test, the CV was not available for this test. The heat release and chemical shrinkage values at 3 and 7 days were used to evaluate the reproducibility for these continuous tests.

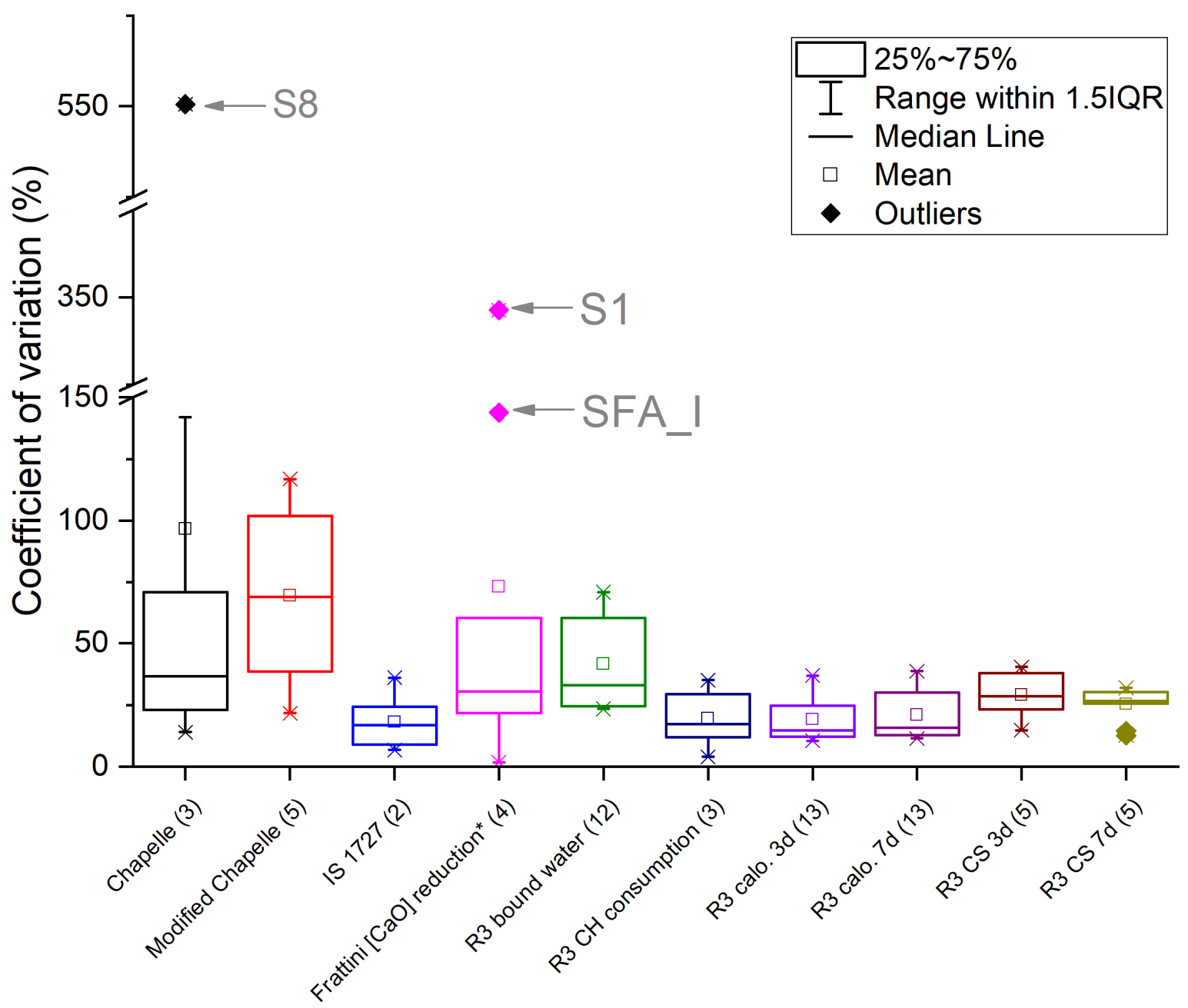

Figure 4 Box chart for coefficient of variation (CV) for different methods, numbers in parentheses along the $x$-axis refer to the number of participants. $R^{3} C H$ consumption refers to portlandite consumption for $R^{3}$ model test; $R^{3}$ calo. $3 d$ and $R^{3} C S 3 d$ refer to calorimetry heat release and chemical shrinkage for the $R^{3}$ model, respecitively.

\section{Discussion: Evaluation of the methods}

The test methods were evaluated based on the correlation to the benchmark (relevance) and the interlaboratory reproducibility (reliability). Other factors such as test duration, complexity and cost of equipment also need to be taken into consideration. Figure 5 shows the $\mathrm{CV}$ against the $R^{2}$ value for the correlation to the 28 days relative strength. An ideal test should be located as close as possible to 1.0 on the $R^{2}$ scale while showing the lowest CV in Figure 5. The dotted blue line corresponds to $R^{2}=0.85$. The results are summarized and compared to the 
other factors for each reactivity method in Table 5. In the following sections the results for the reactivity test methods are discussed one by one.

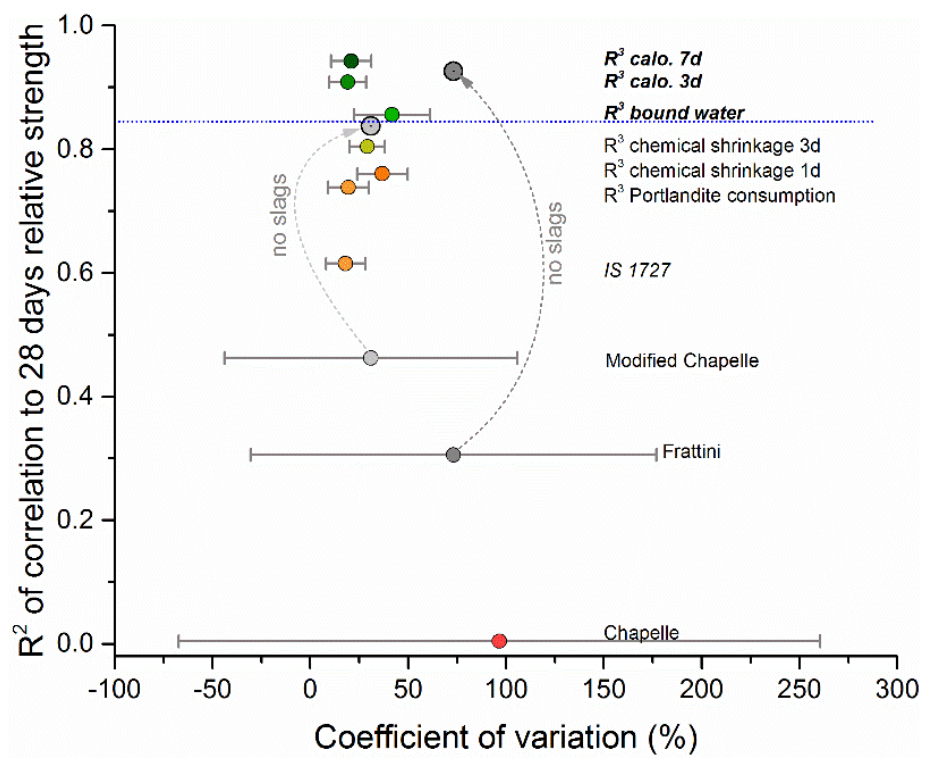

Figure 5 Correlation to 28 days relative strength vs. coefficient of variation (CV) plot, dotted blue line corresponds to $R^{2}$ value equal to 0.85 , dashed grey arrows indicate the improvement of the correlation for Frattini and Modified Chapelle tests by exclusion of the slag.

Table 5 Summary of the methods, ranked based on the correlation to 28 days relative compressive strength.

\begin{tabular}{|c|c|c|c|c|c|c|}
\hline \multirow{2}{*}{ Methods } & \multirow{2}{*}{$\begin{array}{l}\text { Correlation } \\
\text { to } 28 \mathrm{~d} \\
\text { relative } \\
\text { strength }^{(\mathrm{a})}\end{array}$} & \multirow{2}{*}{$\begin{array}{l}\text { Coefficient of } \\
\text { variation }\end{array}$} & \multicolumn{2}{|c|}{ Time } & \multirow{2}{*}{$\begin{array}{l}\text { Equipment } \\
\text { investment }\end{array}$} & \multirow{2}{*}{$\begin{array}{c}\text { Key } \\
\text { equipment }\end{array}$} \\
\hline & & & Operating & $\begin{array}{c}\text { Test } \\
\text { duration }\end{array}$ & & \\
\hline Units & -- & $\%$ & Hours & days & relative $^{(\mathrm{c})}$ & -- \\
\hline $\mathrm{R}^{3}$ calorimetry 7 days & 0.94 & 20.9 & 1 & 7 & 20 & Calorimeter \\
\hline $\mathrm{R}^{3}$ calorimetry 3 days & 0.91 & 19.1 & 1 & 3 & 20 & Calorimeter \\
\hline $\mathrm{R}^{3}$ bound water & 0.86 & 41.7 & 2 & 8 & 2 & Oven \\
\hline $\mathrm{R}^{3}$ chemical shrinkage 3 days & 0.80 & 29.1 & 4 & 3 & 2 & Water bath \\
\hline $\mathrm{R}^{3}$ portlandite consumption & 0.74 & 19.5 & 2 & 8 & 10 & TG \\
\hline IS 1727 (Indian standard) & 0.62 & 18.1 & 1 & 10 & 2 & $\begin{array}{l}\text { Compression } \\
\text { testing } \\
\text { equipment }\end{array}$ \\
\hline Modified Chapelle & 0.46 & 30.9 & 2 & 1 & 1 & $\begin{array}{l}\text { Reflux } \\
\text { condenser }\end{array}$ \\
\hline Frattini $([\mathrm{CaO}]$ reduction $)$ & 0.31 & 73.1 & 2 & 8 & 1 & Glass, pipettes \\
\hline Reactive silica & 0.31 & - - $^{(b)}$ & 2 & 1 & 2 & Glass, oven \\
\hline Chapelle test & 0.00 & 96.6 & 2 & 1 & 1 & $\begin{array}{l}\text { Reflux } \\
\text { condenser }\end{array}$ \\
\hline
\end{tabular}

Notes: (a), $R^{2}$ of the linear fitting; (b) no data as there is only one input; (c) relative cost. 


\subsection{Standard reactivity test methods}

\section{Chapelle and modified Chapelle test}

The Chapelle test showed no correlation to the 28 days relative strength. The Modified Chapelle test showed poor correlation $\left(R^{2}=0.46\right)$ because the results for slag fell out of the linear trend as this method is not suitable for (latent) hydraulic SCMs. When excluding the slags, the $R^{2}$ correlation coefficient is improved from 0.46 to 0.84 for the modified Chapelle test (see Figure 2 (b), Figure 5, Table 4, and Supplementary Material). The Chapelle test showed the worst reproducibility (mean $\mathrm{CV}=96 \%$ ) of all tests. The improved protocols of the modified Chapelle test resulted in significantly less dispersion of results with a mean CV of $31 \%$. However, the committee noted that the experimental set-up is rather complex, and much care is required to control the experiment and avoid carbonation.

\section{Frattini test}

The Frattini test also showed poor correlation to the 28 days relative strength. The results for slags fell out of the trend for the Frattini test (see Figure 2 (c)). When excluding the slags, the $R^{2}$ correlation coefficient is once again much improved, from 0.31 to 0.93 (see Figure 5, Table 4, and Supplementary Material). This indicates that the Frattini method does perform well for purely pozzolanic materials, but cannot cover SCMs that show a (latent) hydraulic nature. On the other hand, the Frattini test results showed a rather high CV (mean CV $=73 \%$ ), which reflects the use of different local Portland cements with different alkali content.

\section{Indian lime reactivity test (IS 1727)}

The Indian standard lime reactivity test (IS 1727) showed only moderate correlation to the 28 days relative strength benchmark, but better than any other standard method when all SCMs are taken into account. For 90 days strength, however, the IS 1727 test performed best in terms of correlation (see Figure 2 (f) and Table 4). This may be related to the higher curing temperature of $50{ }^{\circ} \mathrm{C}$ and the longer test duration of 10 days as also for the $\mathrm{R}^{3}$ test methods an increase in correlation was found for increased test durations (e.g. compare the $R^{2}$ values for 3 and 7 days $\mathrm{R}^{3}$ test heat release). The CV for IS 1727 is relatively good but less representative because only two laboratories used this technique at this stage, so more testing is required to better constrain the reproducibility of the test.

\section{Reactive silica test}

Reactive silica test did not give acceptable correlation to the compressive strength results. The reproducibility could not be assessed as the test was only carried out by one participant. 


\section{2 $\quad \mathrm{R}^{3}$ methods}

Both the $\mathrm{R}^{3}$ bound water and calorimetry tests gave good correlations passing the acceptance criterion. For methods compared to 28 days relative strength with $R^{2}$ higher than $0.85\left(\mathrm{R}^{3}\right.$ calorimetry at 7 and 3 days, and bound water test), the linear fitting to the 28 days relative strength is shown in the plots in the Supplementary Material.

With respect to early strength ( 7 days relative strength), the $\mathrm{R}^{3}$ model systems perform better than the standard methods. The correlation coefficients were greater than 0.85 for all measurement methods, with the exception of the 14 days chemical shrinkage measurements. The $\mathrm{CV}$ for the $\mathrm{R}^{3}$ model tests were relatively low, better than those of the standard tests.

\section{$R^{3}$ calorimetry test}

The $\mathrm{R}^{3}$ calorimetry test showed the best correlation to 28 days relative strength with an $R^{2}$ of 0.94 for the heat release results taken at 7 days (as shown in Table 5), and the correlation to the 3 days cumulative heat was also acceptable. The cumulative heat at shorter ages ( 0.5 and 1 day) gave the best correlation to the 7 days strength measurements. This indicates that different time intervals in the continuous measurements may be selected for correlation to the compressive strength at different ages. It can be observed in Table 4 that the $\mathrm{R}^{3}$ heat release correlates better with the 90 days strength as the total heat is calculated at longer times. The relatively low CV indicates good reproducibility of the results. As a drawback, the equipment cost of an isothermal conduction calorimeter is relatively high. This is partially mitigated by the relatively low staff effort required compared to more laborious standard tests (see Table 5).

\section{$R^{3}$ bound water test}

The $\mathrm{R}^{3}$ bound water test showed acceptable correlations to the 28 days relative strength with an $R^{2}$ of 0.86 for the linear correlation. Even though the linear correlation is not as good as that for the calorimetry at 7 days, the simplicity and the relatively low cost of the equipment needed (see Table 5) would enable widespread use of this test. Between the different methods for the $\mathrm{R}^{3}$ system, the bound water test has the highest CV (42\%). While the equipment used in this test is inexpensive and widely available in basic cement laboratories, the measurement protocol requires more staff effort (see Table 5). However, the technique is straightforward and does not require advanced training.

\section{$R^{3}$ portlandite consumption test}


The $\mathrm{R}^{3}$ portlandite consumption test showed a rather weak correlation to the strength benchmark as the results of slags biased the linear trend (see Figure 3 (b)). Similarly to the Frattini and modified Chappelle tests, the correlation is much improved when the results for the slags are removed from the analysis. The relatively low $\mathrm{CV}$ indicates good reproducibility of the results. The current protocol requires thermogravimetric equipment which is costly, in addition the need for hydration stoppage (here by solvent exchange) makes the test rather laborious and introduces an additional source of variation.

\section{$R^{3}$ chemical shrinkage test}

The $\mathrm{R}^{3}$ chemical shrinkage test did not give acceptable correlations to the 28 days relative strength (see Figure 3 (d)). The relationships between early age chemical shrinkage and strength appear to be non-linear, moreover later age chemical shrinkage results did not show an improvement of the correlation to the 28 days relative strength. The rather low CV indicates fair reproducibility of the results. The chemical shrinkage measurement apparatus is inexpensive, however correct execution of the measurement requires experience. Notably the loading of the containers with the paste is difficult and may strongly affect the results.

\subsection{Preliminary conclusions}

Only tests based on the $\mathrm{R}^{3}$ system gave good performance across the whole range of SCMs investigated. Standardized methods conceived for pozzolans perform poorly when slag is included (Frattini, modified Chapelle test). Some standardized methods, e.g. reactive silica, did not show correlation to the benchmark strength development.

\section{Conclusions and perspectives}

This paper reports on an extensive multi-laboratory evaluation of SCM reactivity test methods carried out as part of the work of RILEM TC-267 TRM.

When taking all SCMs into consideration, all standardized methods showed poor correlation to the benchmark of 28 days relative strength. In contrast, the $\mathrm{R}^{3}$ model calorimetry and bound water tests were able to give acceptable correlations, i.e. $R^{2}>0.85$. When slags are excluded, the correlation of the Frattini test results becomes acceptable as well and the one of the modified Chapelle test increases but remains slightly lower than the acceptable correlation value. The IS 1727 test is the only method that gave reasonable correlation to the later age 90 days relative strength, possibly because of its longer duration than most other tested methods. 
The Chapelle showed the worst interlaboratory reproducibility while Frattini test and modified Chapelle test had better reproducibility. The reproducibility of the $\mathrm{R}^{3}$ model tests was the best of all the methods investigated, and can probably be improved by specifying in more detail some critical aspects in the execution of the tests.

In the phase 2 work of RILEM TC 267-TRM, the $\mathrm{R}^{3}$ model bound water and calorimetry will be further studied due to their very promising correlations to the relative 28 days compressive strength. Further work will focus on improving the reproducibility of these methods by optimizing the test protocols. Possibilities to reduce the duration and improve correlations with early age strength development for the IS1727 test will also be included in the work for phase 2 .

\section{Acknowledgements}

Francois Avet (EPFL, Switzerland), Luigi Brunetti (Empa, Switzerland), Nele De Belie (Ghent University, Belgium), Paweł T. Durdziński (HeidelbergCement Technology, Germany), Alexandre Ouzia (EPFL, Switzerland), Olga Perebatova (Univeristy of Toronto, Canada), Yury Villagrán Zaccardi (Ghent University, Belgium) and Bing Wang (Sinoma, China) are gratefully acknowledged for their contribution to this work.

\section{Fundings}

A. Parashar and S. Bishnoi acknowledge financial support by the Swiss Agency for Development and Cooperation (SDC) grant 81026665 .

A. M. Joseph acknowledges the financial support from the foundations SIM (Strategic Initiative Materials in Flanders) and VLAIO (Flanders Innovation \& Entrepreneurship) of Project ASHCEM within the program "MARES"

S. Kramar acknowledges the financial support from the Slovenian Research Agency (research core funding No. P2-0273).

T. Sui acknowledges the support by National Key R\&D Program of China (2016YFE0206100 and 2017YFB0310905) financed by the Ministry of Science and Technology of the People's Republic of China (MOST).

\section{Compliance with ethical standards}

\section{Conflict of interest}

All co-authors are members in RILEM TC 267-TRM. None of the co-authors has financial conflict of interest. 


\section{References}

1. Chapelle J (1958) Attaque sulfocalcique des laitiers et pouzzolanes. Rev Matér Constr 512:136-145

2. Raverdy M, Brivot F, Paillère A, Bron R (1980) Appréciation de l'activité pouzzolanique de constituents secondaires. Proceedings of 7e congrés international de la chimie des ciments, Paris, France:6-41

3. Frattini N (1949) Richerche sulla calce di idrolisi nelle paste di cimento. Ann di Chim Appl 39:616-620

4. Snellings R, Scrivener K (2015) Rapid screening tests for supplementary cementitious materials: past and future. Mater Struct:1-15. doi:10.1617/s11527-015-0718-z

5. Lothenbach B, Scrivener K, Hooton RD (2011) Supplementary cementitious materials. Cem Concr Res 41 (12):1244-1256. doi:http://dx.doi.org/10.1016/j.cemconres.2010.12.001

6. Scrivener KL, Lothenbach B, De Belie N, Gruyaert E, Skibsted J, Snellings R, Vollpracht A (2015) TC 238-SCM: hydration and microstructure of concrete with SCMs State of the art on methods to determine degree of reaction of SCMs. Mater Struct 48 (4):835-862. doi:10.1617/s11527-015-0527-4

7. Avet F, Snellings R, Alujas Diaz A, Ben Haha M, Scrivener K (2016) Development of a new rapid, relevant and reliable (R3) test method to evaluate the pozzolanic reactivity of calcined kaolinitic clays. Cem Concr Res 85:111. doi:http://dx.doi.org/10.1016/j.cemconres.2016.02.015

8. Suraneni P, Weiss J (2017) Examining the pozzolanicity of supplementary cementitious materials using isothermal calorimetry and thermogravimetric analysis. Cem Concr Comp 83:273-278. doi:https://doi.org/10.1016/j.cemconcomp.2017.07.009

9. Durdziński PT, Ben Haha M, Bernal SA, De Belie N, Gruyaert E, Lothenbach B, Menéndez Méndez E, Provis JL, Schöler A, Stabler C, Tan Z, Villagrán Zaccardi Y, Vollpracht A, Winnefeld F, Zając M, Scrivener KL (2017) Outcomes of the RILEM round robin on degree of reaction of slag and fly ash in blended cements. Mater Struct 50 (2):135. doi:10.1617/s11527-017-1002-1

10. Kocaba V, Gallucci E, Scrivener KL (2012) Methods for determination of degree of reaction of slag in

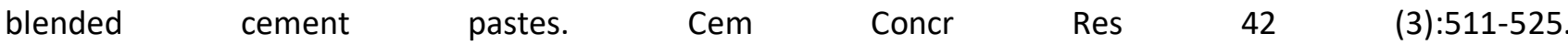
doi:http://dx.doi.org/10.1016/j.cemconres.2011.11.010

11. Helsel MA, Ferraris CF, Bentz D (2015) Comparative study of methods to measure the density of Cementitious powders. J Test Eval 44 (6):2147-2154

12. Antoni M, Rossen J, Martirena F, Scrivener K (2012) Cement substitution by a combination of metakaolin and limestone. Cem Concr Res 42 (12):1579-1589. doi:http://dx.doi.org/10.1016/i.cemconres.2012.09.006

13. Donatello S, Tyrer M, Cheeseman CR (2010) Comparison of test methods to assess pozzolanic activity. Cem Concr Comp 32 (2):121-127. doi:https://doi.org/10.1016/j.cemconcomp.2009.10.008

14. Snellings R, Chwast J, Cizer Ö, De Belie N, Dhandapani Y, Durdzinski P, Elsen J, Haufe J, Hooton D, Patapy C, Santhanam M, Scrivener K, Snoeck D, Steger L, Tongbo S, Vollpracht A, Winnefeld F, Lothenbach B (2018) Report of TC 238-SCM: hydration stoppage methods for phase assemblage studies of blended cementsresults of a round robin test. Mater Struct 51 (4):111. doi:10.1617/s11527-018-1237-5

15. Snellings R, et.al. (2018) TC 238-SCM: RILEM TC-238 SCM recommendation on hydration stoppage by solvent exchange for the study of hydrate assemblages. Mater Struct under review

16. Lothenbach B, De Weerdt K (2016) Thermogravimetric analysis. In: A Practical Guide to Microstructural Analysis of Cementitious Materials. CRC Press Oxford, UK, pp 177-212

17. Geiker M (2016) Characterisation of development of cement hydration using chemical shrinkage. In: A Practical Guide to Microstructural Analysis of Cementitious Materials. CRC Press Oxford, UK, pp 75-105 